University of Wollongong

Research Online

Faculty of Engineering and Information

Faculty of Engineering and Information

Sciences - Papers: Part A

Sciences

2017

\title{
Displaced hardness peak phenomenon in heat-affected zone of welded quenched and tempered EM812 steel
}

Druce P. Dunne

University of Wollongong, druce@uow.edu.au

W Pang

Bisalloy Steels

Follow this and additional works at: https://ro.uow.edu.au/eispapers

Part of the Engineering Commons, and the Science and Technology Studies Commons

Research Online is the open access institutional repository for the University of Wollongong. For further information contact the UOW Library: research-pubs@uow.edu.au 


\title{
Displaced hardness peak phenomenon in heat-affected zone of welded quenched and tempered EM812 steel
}

\begin{abstract}
Investigations of microstructural and hardness gradients in the heat-affected zone (HAZ) of quenched and tempered (Q\&T) steels have indicated that peak hardness does not occur in the grain-coarsened heataffected zone (GCHAZ) adjacent to the fusion boundary, which is typical of ferritic steels, but corresponds more closely to the grain-refined region (GRHAZ). This phenomenon, the displaced hardness peak (DHP) effect, is considered to arise when the hardenability of the steel is high enough to result in the same microstructure in the GC and GR heat-affected zones, except for significant refinement of the microstructure of the GRHAZ, which increases the hardness and strength above those of the GCHAZ. The current paper concentrates on the effect of grain size on hardness in the HAZ of a boron-containing lowcarbon martensitic steel subjected to bead-on-plate welding. Thermal simulation experiments were used to clarify the relationship between prior austenite grain size and the hardness gradients in the actual HAZ. The simulation work demonstrated that peak hardness in simulation samples occurred in regions of lower austenite grain size, supporting the proposed origin of the DHP effect in actual welds. Implications regarding hydrogen-induced cold cracking (HICC) susceptibility of the GRHAZ are discussed.
\end{abstract}

\section{Keywords}

phenomenon, peak, steel, hardness, em812, displaced, tempered, quenched, welded, zone, heat-affected

\section{Disciplines}

Engineering | Science and Technology Studies

\section{Publication Details}

Dunne, D. P. \& Pang, W. (2017). Displaced hardness peak phenomenon in heat-affected zone of welded quenched and tempered EM812 steel. Welding in the World, 61 (1), 57-67. 


\title{
Displaced Hardness Peak Phenomenon in Heat Affected Zone of Welded \\ Quenched and Tempered EM812 Steel
}

\author{
D.P. Dunne ${ }^{\mathrm{a}}$ and W. Pang ${ }^{\mathrm{b}}$
}

a. Faculty of Engineering and Information Sciences, University of Wollongong, Wollongong, NSW,

Australia, 2522.

<druce@uow.edu.au>

b. Export and Armour Manager, Bisalloy Steels, Unanderra, NSW, Australia, 2526.

<willy.pang@bisalloy.com.au>

Keywords: heat affected zone, hardness gradients, quenched and tempered steels, HICC susceptibility

\begin{abstract}
Investigations of microstructural and hardness gradients in the heat affected zone (HAZ) of quenched and tempered (Q\&T) steels have indicated that peak hardness does not occur in the grain coarsened heat affected zone (GCHAZ) adjacent to the fusion boundary, which is typical of ferritic steels, but corresponds more closely to the grain refined region (GRHAZ). This phenomenon, the displaced hardness peak (DHP) effect, is considered to arise when the hardenability of the steel is high enough to result in the same microstructure in the GC and GR heat affected zones, except for significant refinement of the microstructure of the GRHAZ, which increases the hardness and strength above those of the GCHAZ. The current paper concentrates on the effect of grain size on hardness in the HAZ of a boron-containing low carbon martensitic steel subjected to bead-on-plate welding. Thermal simulation experiments were used to clarify the relationship between prior austenite grain size and the hardness gradients in the actual HAZ. The simulation work demonstrated that peak hardness in simulation samples occurred in regions of lower austenite grain size, supporting the proposed origin of the DHP effect in actual welds. Implications regarding HICC-susceptibility of the GRHAZ are discussed.
\end{abstract}

\section{Introduction}

Low-carbon quenched and tempered (Q\&T) steels are designed for applications requiring both high strength and good weldability. USS “T1” type A, low-carbon martensitic steel [1], has served as a template for modern Q\&T steels that are alloy-lean, and especially low in carbon, in order to improve 
weldability and decrease the susceptibility to hydrogen embrittlement. Boron additions are commonly used to maintain hardenability.

As supplied Q\&T steel plate has a structure of well tempered martensite with a minimum yield strength of $690 \mathrm{MPa}$ and a hardness higher than about $220 \mathrm{HV}$. Welding produces local hardening of the HAZ of the parent plate due to formation of martensite or bainite which, in the absence of pre-heat or post-weld heat treatment, is effectively untempered. Bainite is possible instead of, or in addition to, martensite as the cooling rates during welding are typically lower than those achieved by water spray quenching in plate processing.

During the weld thermal cycle, regions of the HAZ that experience temperatures above $\mathrm{A}_{\mathrm{C} 3}$ are fully reaustenitised and can subsequently transform to martensite/bainite on cooling. An austenite grain size gradient is also established with the coarsest grains forming adjacent to the fusion boundary (in the GCHAZ). The mean austenite grain size $\left(\mathrm{d}_{\mathrm{A}}\right)$ decreases as the peak temperature falls, with an accompanying decrease in hardenability. Thus, the hardness gradient across the parent metal HAZ typically shows a maximum hardness immediately adjacent to the fusion boundary with a progressive decrease across the GCHAZ, the GRHAZ $\left(\sim 1100^{\circ} \mathrm{C}\right.$ to $\left.A_{C 3}\right)$, and the intercritical heat affected zone (ICHAZ), which is bounded by $\mathrm{A}_{\mathrm{C} 3}$ and $\mathrm{A}_{\mathrm{C} 1}$ and is only partially re-austenitised.

$\mathbf{H}$

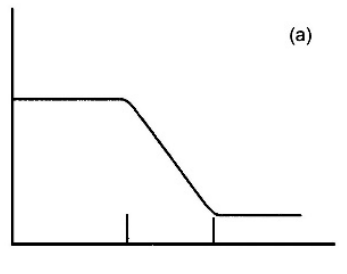

WM HAZ PM

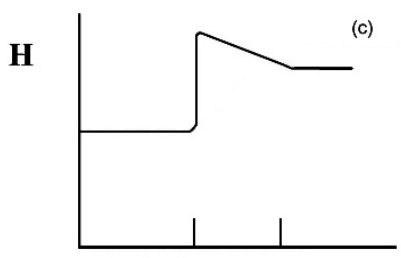

WM HAZ PM

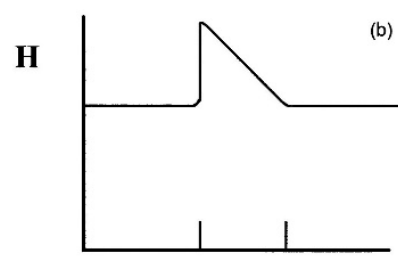

WM HAZ PM

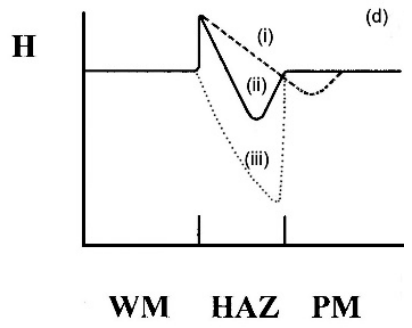

Figure 1. Schematic hardness profiles across the HAZ for weld metal that is (a) overstrength; (b) strength-matching; (c) under-strength; and (d) strength-matching with softening in the parent metal curve (i), in the ICHAZ (ii) and over the whole HAZ (iii). After Ref. 2. 
Various schematic hardness profiles across the weld metal, the HAZ and the parent metal are shown in Figure 1 as a function of the relative strengths of the weld and parent metals. The hardness trend shown in Figure 1(b) applies particularly to welded low carbon structural steels and high strength low alloy steels (HSLA) with essentially ferritic/pearlitic microstructures and yield strengths below about 550 $\mathrm{MPa}$. These types of steels have a carbon equivalent $\left(\mathrm{CE}_{\mathrm{IIW}}\right)$ lower than 0.4 , which is specified by the International Institute of Welding [3] as the upper limit for welding without pre-heat, provided the heat input and the weld configuration are appropriate to prevent rapid cooling. The schematic hardness profiles shown in Figure 1(d), curves (i) and (ii), are based on experimental studies [4] of a low carbon A710 type steel $(1 \% \mathrm{Ni}, 1 \% \mathrm{Cu})$ which is strengthened in the controlled rolled condition by $\mathrm{Cu}$ precipitation hardening. This strengthening contribution can be diminished in the HAZ as a result of welding. Figure 2(a) shows the HAZ hardness gradient for this type of steel for the specified welding for welding of BIS60 - an alloy-lean Q\&T steel of marginal hardenability $\left(\mathrm{CE}_{\mathrm{IIW}}=0.43\right.$ ) and a minimum specified yield strength of $500 \mathrm{MPa}$ [5]. Typical weld cooling rates result in transformation at relatively high temperatures to ferritic products with a hardness profile across the HAZ that lies below the average hardness of the base Q\&T steel.

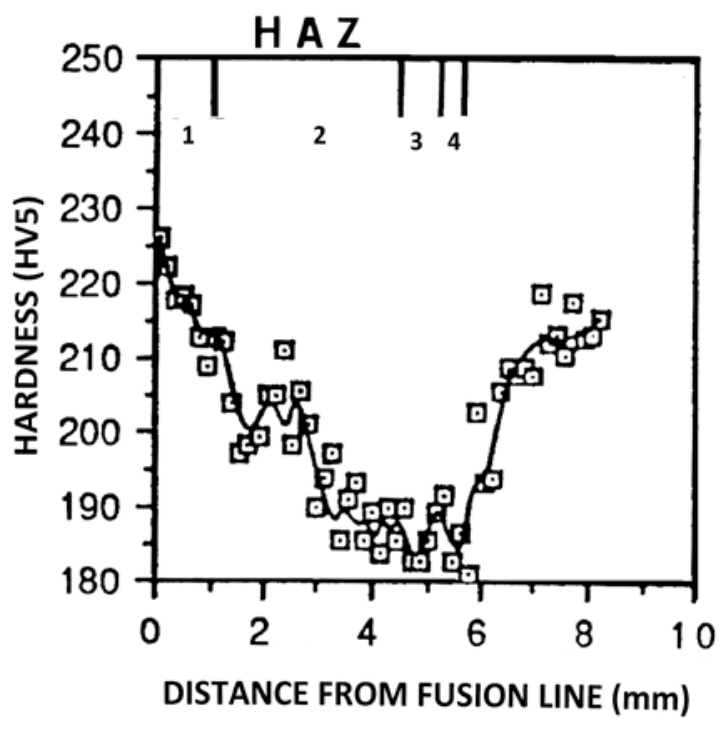

(a)

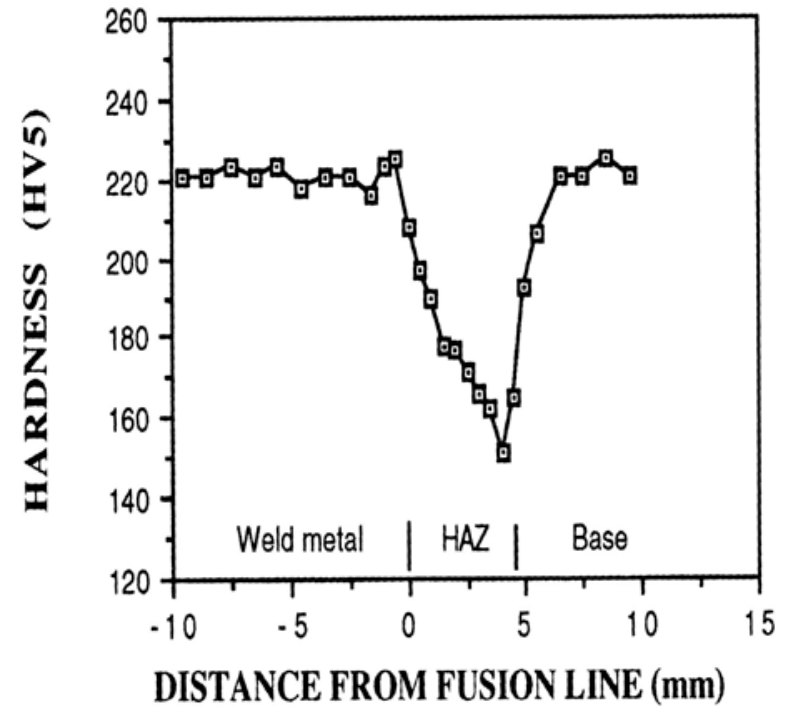

(b)

Figure 2. (a) Hardness traverse across the HAZ of a BOP submerged arc $6 \mathrm{~kJ} / \mathrm{mm}$ weld on a Cubearing A710 type plate steel of $20 \mathrm{~mm}$ thickness. The numerals 1 to 4 represent respectively the GCHAZ, GRHAZ, ICHAZ and the tempered base plate [4]. (b) Hardness traverse across HAZ of $20 \mathrm{~mm}$ BIS60 plate, welded at $5 \mathrm{~kJ} / \mathrm{mm}$ heat input by 4-wire SAW [5].

For Q\&T steels of higher hardenability $\left(\mathrm{CE}_{\text {IIW }}>0.5\right)$ pre-heat is usually specified for arc welding in order to reduce the cooling rate and thereby decrease HAZ hardening and susceptibility to HICC. Unusual HAZ hardness profiles were reported recently for a series of high strength Q\&T steels [2]. The peak HAZ hardness was found to occur in the GRHAZ and the phenomenon was described as the 
“displaced hardness peak” (DHP) effect. Similar results were obtained for three 690 MPa Q\&T steels: BIS80, EM812 and an experimental low carbon, Cu-bearing Q\&T steel [2, 5-7]. Although these steels are classified as martensitic, bainitic ferrite was found to be the dominant microstructure in the HAZ under typical arc welding conditions for a wide range of plate thicknesses.

The inference of a DHP effect can be challenged because of the difficulty in identifying the fusion boundary, the possible influence of a partly molten and intermixed zone and interdiffusion between the molten weld bead and the base plate. In order to resolve this issue, thermal simulations were carried out on $12 \mathrm{~mm}$ thick EM812 plate steel using peak temperatures and cooling rates consistent with those experienced by the GCHAZ and GRHAZ for typical welding conditions. This work confirmed that the peak hardness did not correspond to the peak temperature reached at the centre of the simulation sample $[2,6,7]$. The current paper addresses the austenite grain size gradients in the HAZ in more detail for both actual welds and for samples subjected to simulated thermal cycles by resistance heating. Further, the microstructures and hardness profiles are critically compared for the actual welds and the simulated weld thermal cycles.

\section{Experimental Methods}

The composition of the $690 \mathrm{MPa}$ Q\&T steel investigated is given in Table 1, together with plate thickness and the carbon equivalent. The steel contains boron to counteract the hardenability loss due to the relatively low carbon content and limited concentrations of alloying elements. Details of the submerged arc welding procedures are given in Table $2[2,6]$.

Table 1. Composition (wt \%) of 12 mm EM812 plate steel.

\begin{tabular}{|l|c|c|c|c|c|c|c|c|c|c|c|c|c|c|}
\hline Steel & $\mathrm{C}$ & $\mathrm{Mn}$ & $\mathrm{P}$ & $\mathrm{Si}$ & $\mathrm{S}$ & $\mathrm{Ni}$ & $\mathrm{Cr}$ & $\mathrm{Mo}$ & $\mathrm{Cu}$ & $\mathrm{Al}$ & $\mathrm{Ti}$ & $\mathrm{B}$ & $\mathrm{V}$ & $\mathrm{CE}$ \\
\hline EM812 $12 \mathrm{~mm}$ & 0.12 & 0.90 & 0.015 & 0.25 & 0.002 & 1.25 & 0.51 & 0.36 & 0.19 & 0.060 & 0.005 & 0.0015 & 0.017 & 0.532 \\
& & & & & & & & & & & & & & \\
\hline
\end{tabular}

Table 2. Q\&T treatment, basic mechanical properties and the welding conditions.

\begin{tabular}{|c|c|c|c|c|c|c|c|c|c|}
\hline Steel & Heat Treatment & $\begin{array}{l}\mathrm{YS} \\
(\mathrm{MPa})\end{array}$ & $\mathrm{HV}$ & Welding Process & $\begin{array}{l}\text { Heat input } \\
(\mathrm{kJ} / \mathrm{mm})\end{array}$ & Passes & Prep. & $\begin{array}{l}\text { Filler } \\
\text { Wire }\end{array}$ & Flux \\
\hline $\begin{array}{l}\text { EM812 } \\
12 \mathrm{~mm}\end{array}$ & 925C(WQ); 690C(T) & $>690$ & 250 & BOP SAW & 2.58 & $1 *$ & None & $\begin{array}{l}\text { LA } 100 \\
2.4 \mathrm{~mm}\end{array}$ & $880 \mathrm{M}$ \\
\hline
\end{tabular}

* Preheats of 20, 80, 120 and $200{ }^{\circ} \mathrm{C}$.

A laboratory-built thermal simulator was used to reproduce the actual BOP weld cooling cycle in the centre of the test bar, $110 \mathrm{~mm}$ x $11 \mathrm{~mm}$ x 11mm, which was supported horizontally between water cooled cast iron grips [8]. Setting a $25 \mathrm{~mm}$ sample length between the grips allowed the natural cooling 
rate to exceed the rate required to simulate the actual weld thermal cycle. Test bars were resistance heated at a rate of $250^{\circ} \mathrm{C} / \mathrm{s}$, similar to the heating rate during welding, to a nominal peak temperature of $1350^{\circ} \mathrm{C}$ to simulate the GCHAZ, and to $1100^{\circ} \mathrm{C}$ and $900{ }^{\circ} \mathrm{C}$ to simulate the upper and lower bounds of the GRHAZ. Alternating current was used for heating and cooling by computer control of the current up to a maximum value of 10,000 A, with feedback control using the sample temperature recorded at $1 / 100^{\text {th }} \mathrm{s}$ intervals. Nevertheless, both over- and under-shooting of the selected peak temperature did occur, requiring trial and error adjustments of the aim temperature through the thermal treatment of multiple samples. The cooling in the central region of the bar was controlled at rates defined by data obtained from embedded thermocouples during BOP SAW and also by calculation of the thermal profile.

Hardness (HV) profiles across the weld root, or longitudinally on the surface of simulated samples, were determined using a Vickers Diamond Pyramid indenter at loads of 5 and $10 \mathrm{~kg}$. The standard deviation of hardness measurements was $\pm 5 \mathrm{HV}$ points. Prior austenite grain sizes were determined metallographically by etching in picric acid and using the linear intercept method.

\section{Results and Discussion}

\subsection{HAZ hardness gradients}

Hardness profiles were measured across the HAZs of BOP SAW welds on $12 \mathrm{~mm}$ EM812 plate at 2.58 $\mathrm{kJ} / \mathrm{mm}$ and pre-heats of $20^{\circ} \mathrm{C}$ and $200^{\circ} \mathrm{C}$, Figure 3. Although the weld metal was approximately strengthmatching with the base plate, the hardness profile differed from Figure 1(b) insofar as the peak hardness recorded for a HAZ width of about $2.5 \mathrm{~mm}$ was obtained at a distance of $\sim 1.5 \mathrm{~mm}$ from the fusion boundary. The peak hardness was $\sim 60 \mathrm{HV}$ points lower for the $200^{\circ} \mathrm{C}$ pre-heat, consistent with a cooling time from $800^{\circ} \mathrm{C}$ to $500^{\circ} \mathrm{C}\left(\Delta \mathrm{t}_{8 / 5}\right)$ of about $80 \mathrm{~s}$ for the $200^{\circ} \mathrm{C}$ pre-heat compared to $20 \mathrm{~s}$ for no pre-heat $\left(20^{\circ} \mathrm{C}\right)$. The peak hardness values were about $380 \mathrm{HV}$ and $320 \mathrm{HV}$ for the respective preheats of $20^{\circ} \mathrm{C}$ and $200^{\circ} \mathrm{C}$.

Based on the CCT diagram for this steel, Figure 4, the recorded HAZ cooling times are expected to generate a largely bainitic structure, rather than the fully martensitic structure formed during industrial water quenching. Moreover, micrographs of the GCHAZ structures for the two pre-heats (Figure 4) showed the dominant presence of bainitic ferrite, $\alpha_{B}{ }^{0}[9]$ : ferrite laths with elongated interlath islands of MA (martensite-austenite) constituent, with the structure being coarser for the higher preheat. 


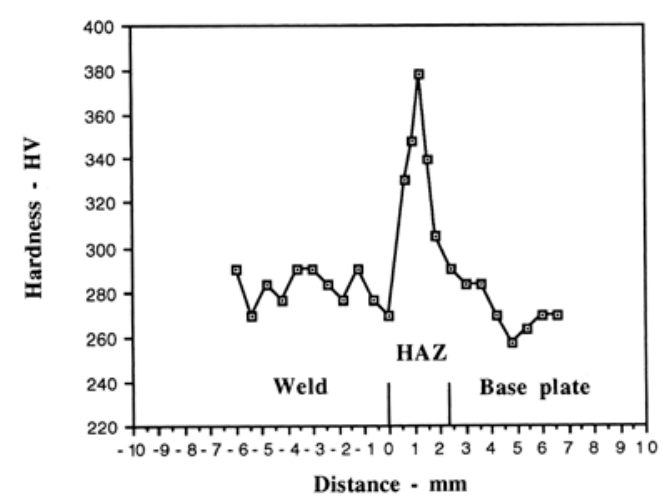

(a)

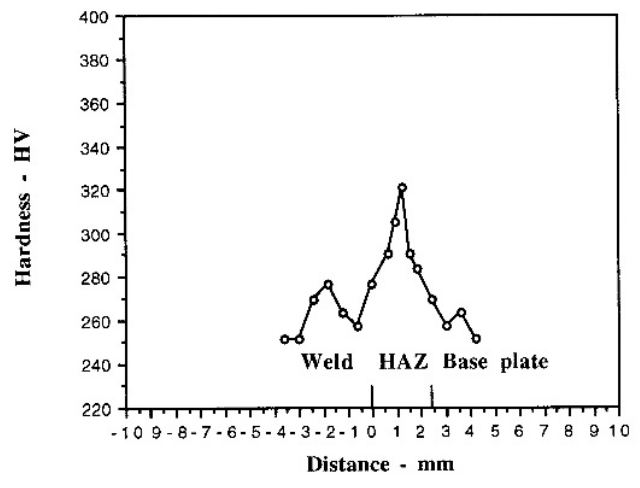

(b)

Figure 3. Vickers hardness (HV5) measurements across the root of BOP SAW welds deposited on $12 \mathrm{~mm}$ EM812 steel at $2.58 \mathrm{~kJ} / \mathrm{mm}$, with pre-heats of $20^{\circ} \mathrm{C}$ (a); and $200^{\circ} \mathrm{C}$ (b). [After Ref. 7].

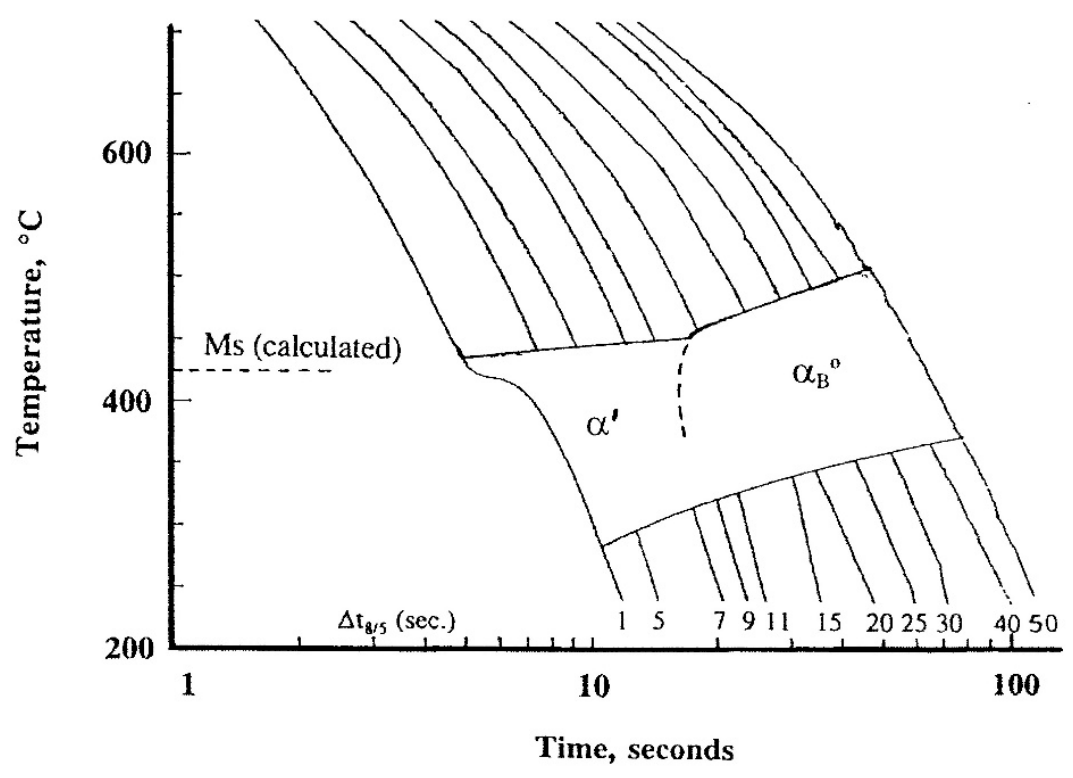

Figure 4. Continuous cooling transformation (CCT) diagram for EM812 steel, austenitised at $1250^{\circ} \mathrm{C}$ for $13 \mathrm{~s}$ and helium cooled at rates corresponding to $\Delta t_{8 / 5}$ values of 1 to $50 \mathrm{~s}$. [After Ref. $10]$.
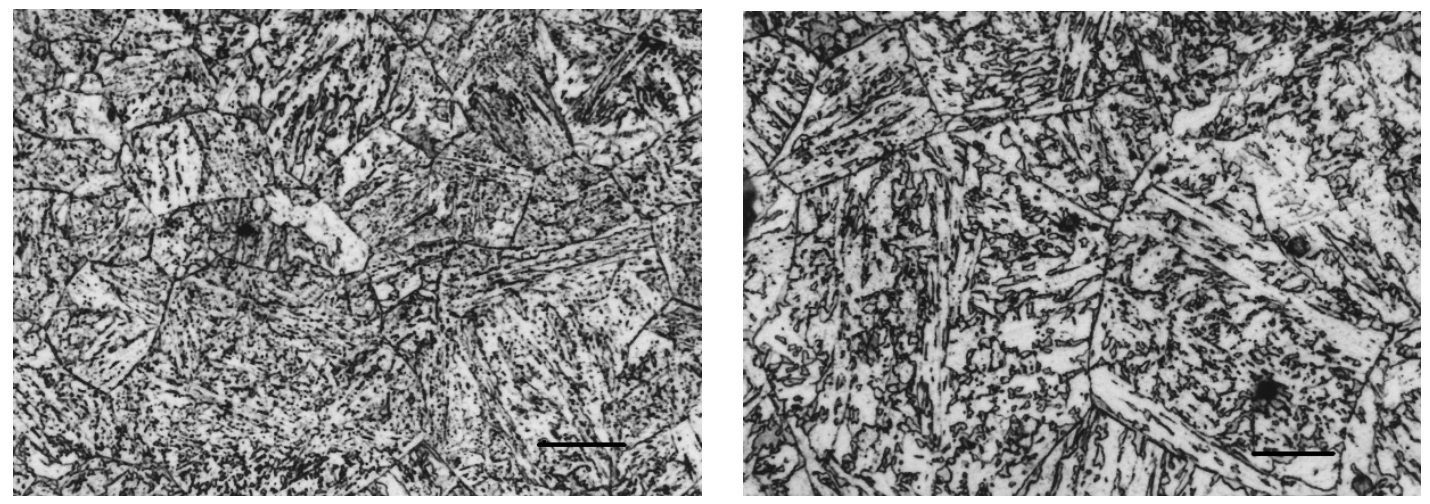

Figure 5. GCHAZ microstructures for BOP welds with $20^{\circ} \mathrm{C}$ (left) and $200^{\circ} \mathrm{C}$ pre-heats. The bar represents $15 \mu \mathrm{m}$. Etched in $2 \%$ Nital. 


\subsection{Simulated weld thermal cycles}

Weld thermal cycle simulation was based on thermal profiles calculated for the actual welds using cooling data obtained from embedded thermocouples. Measurement of the actual thermal profile was performed for welding with no pre-heat, Figure 6(a), and weld thermal cycle simulations closely matched the actual profile, Figures 6(b) and (c). Calculated profiles were obtained by using the simplified version of the Rosenthal analysis [11] given by Easterling [12]. The predicted curves agreed well with the actual, Figure 6(a) and therefore, calculated profiles were used for simulation of the thermal cycles of the samples subjected to preheats of 80, 120 and $200{ }^{\circ} \mathrm{C}$ (see, for example, Figure 6(d) for $200^{\circ} \mathrm{C}$ preheat).

(a)

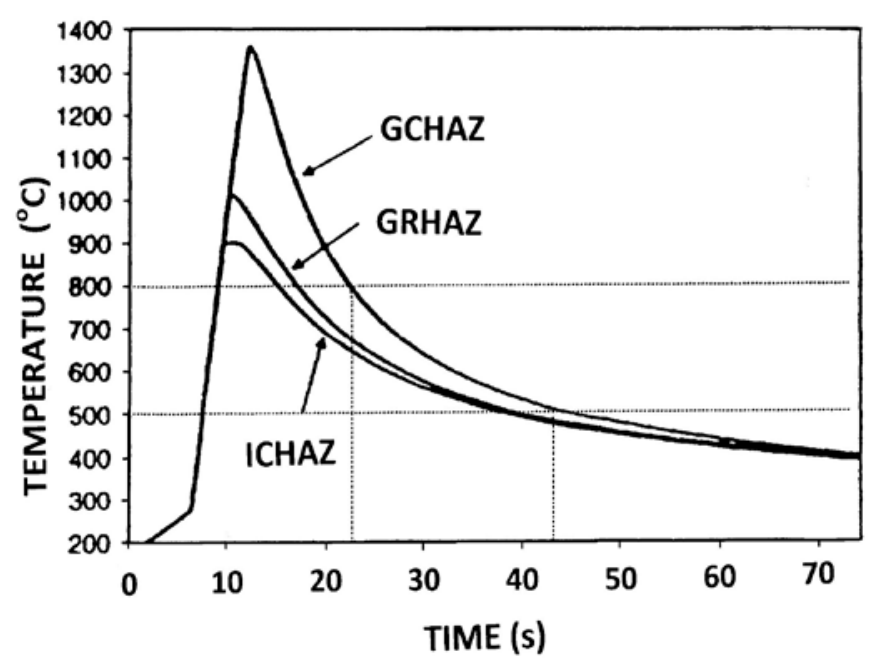

(c)

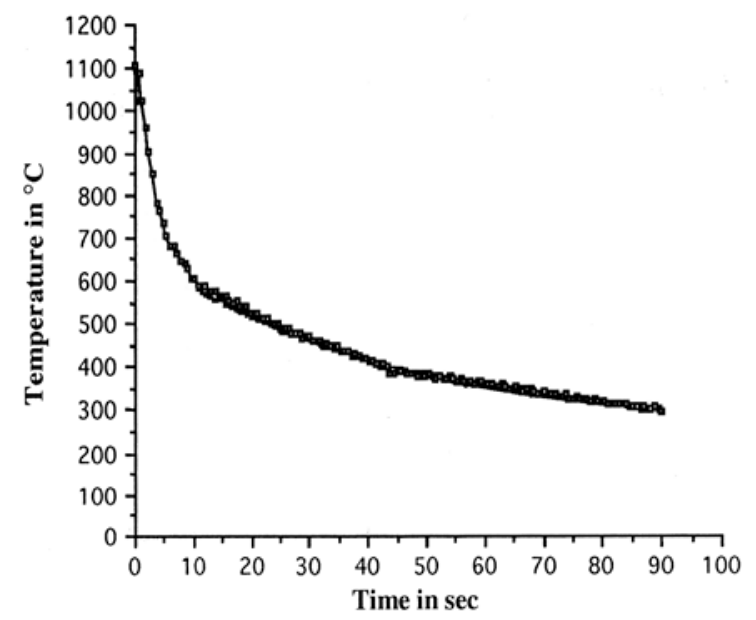

(b)

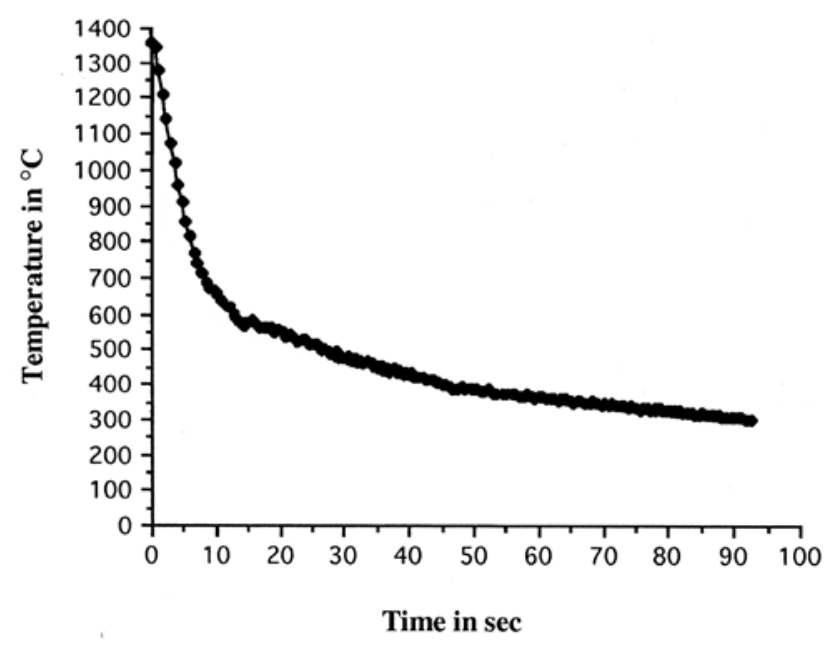

(d)

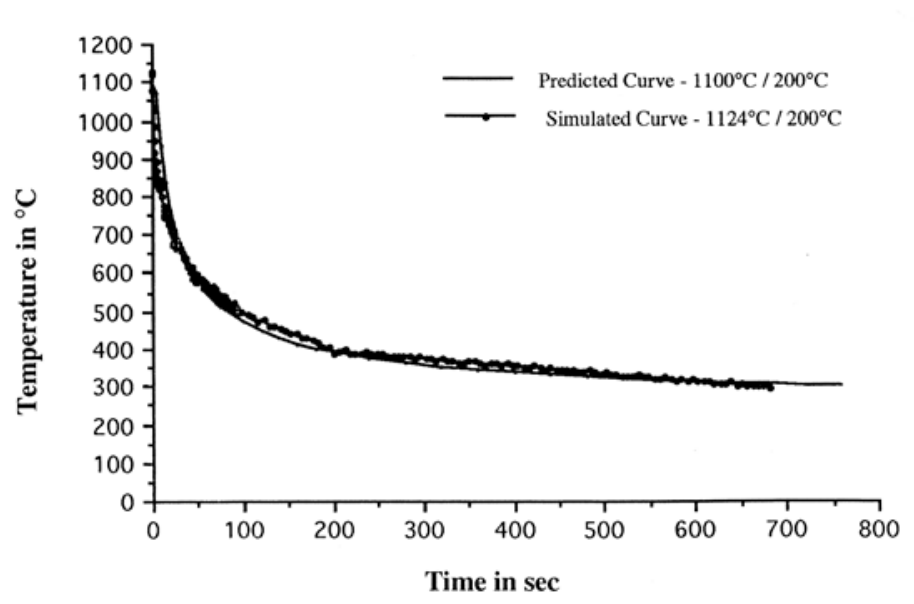


Figure 6. Diagrams showng thermal profiles for (a) actual weld for $20^{\circ} \mathrm{C}$ preheat - data from embedded thermocouples; (b) measured cooling curve for simulated sample heated to a peak temperature of $1346^{\circ} \mathrm{C}$ with $20^{\circ} \mathrm{C}$ preheat; (c) measured cooling curve for simulated sample heated to a peak temperature of $1108^{\circ} \mathrm{C}$ with $20^{\circ} \mathrm{C}$ preheat; and (d) cooling curve for simulated sample heated to a peak temperature of $1124^{\circ} \mathrm{C}$ with $200^{\circ} \mathrm{C}$ preheat and the calculated thermal profile (full line). Note that the peak temperatures obtained on heating is taken to correspond to zero time in (b), (c) and (d).

For peak temperatures of about $1350^{\circ} \mathrm{C}$ and $1100^{\circ} \mathrm{C}$, the $\Delta \mathrm{t}_{8-5}$ values were close to $20 \mathrm{~s}$ for the profiles obtained from embedded thermocouples, as well as for the for simulated cooling curves. For $200^{\circ} \mathrm{C}$ preheat $\Delta \mathrm{t}_{8-5}$ was about $80 \mathrm{~s}$.

It should be noted that the thermal simulation relates to a central volume of metal about $5 \mathrm{~mm}$ in thickness. The thermal gradient along the surface centreline of the bar-shaped samples was previously examined [8] and it was shown (Figure 7) that the measured temperature approximately followed the inverse parabolic form of the equation proposed by Widgery [13]:

$\mathrm{L}=\mathrm{W} \sqrt{ }\left[\Delta \mathrm{T} /\left(\mathrm{T}_{\max }-\mathrm{T}_{\mathrm{o}}\right)\right]$

where $=$ length of sample over which the temperature $\mathrm{T}$ is within $\Delta \mathrm{T}$ of the maximum temperature $\mathrm{T}_{\max }$ $(\mathrm{mm}), \mathrm{T}_{\mathrm{o}}$ is the grip temperature and $\mathrm{W}$ is the sample length between the grips $(\mathrm{mm})$. This temperature gradient, which is determined by the cooling efficiency of the water-cooled grips and the variable power input to the bar, bears no relationship to the much steeper gradient across the actual weld HAZ.

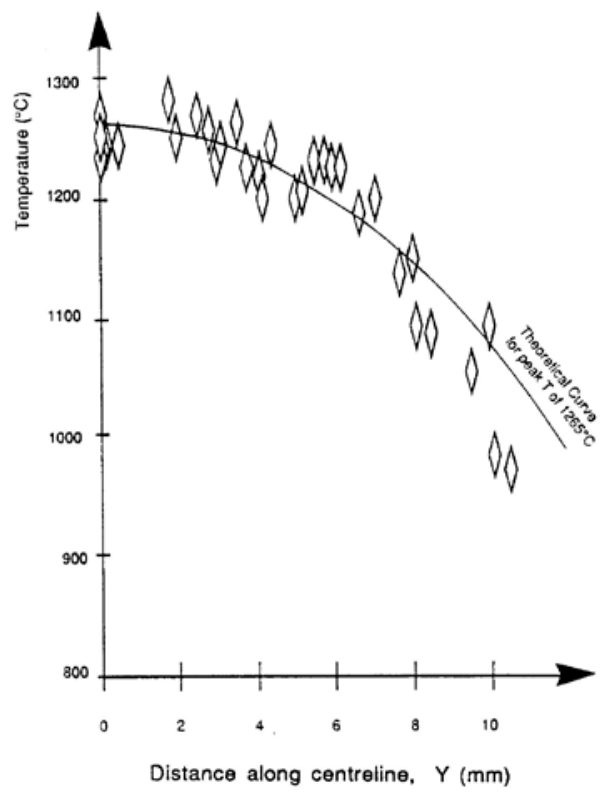

Figure 7. Temperature measurements along the centreline of the bar-shaped simulation sample from the position of the control thermocouple [8]. The full line is the calculated temperature profile determined by Equation (1) [13] for a peak temperature of $1265^{\circ} \mathrm{C}$. 
Previous work [8] also established that the prior austenite grain size was uniform over the central crosssection of the bar, indicating that the thermal gradient perpendicular to the axis of the bar was negligible.

Hardness data for no pre-heat $\left(20^{\circ} \mathrm{C}\right)$ and $200^{\circ} \mathrm{C}$ are given in Figure 8 for simulations based on a peak temperature of $1350{ }^{\circ} \mathrm{C}$ (GCHAZ). The hardness profiles show symmetry, with twin hardness peaks displaced by several millimeters on either side of the central point corresponding to the position of the attached thermocouple. Similar hardness profiles were also recorded for a selected peak temperature of about $1100^{\circ} \mathrm{C}$ (Figure 9). Bainitic ferrite was the dominant microstructure at the centre of the bar (simulated GCHAZ), as well as in the region of maximum hardness. This observation is consistent with the microstructures of the actual welds (Figure 5).
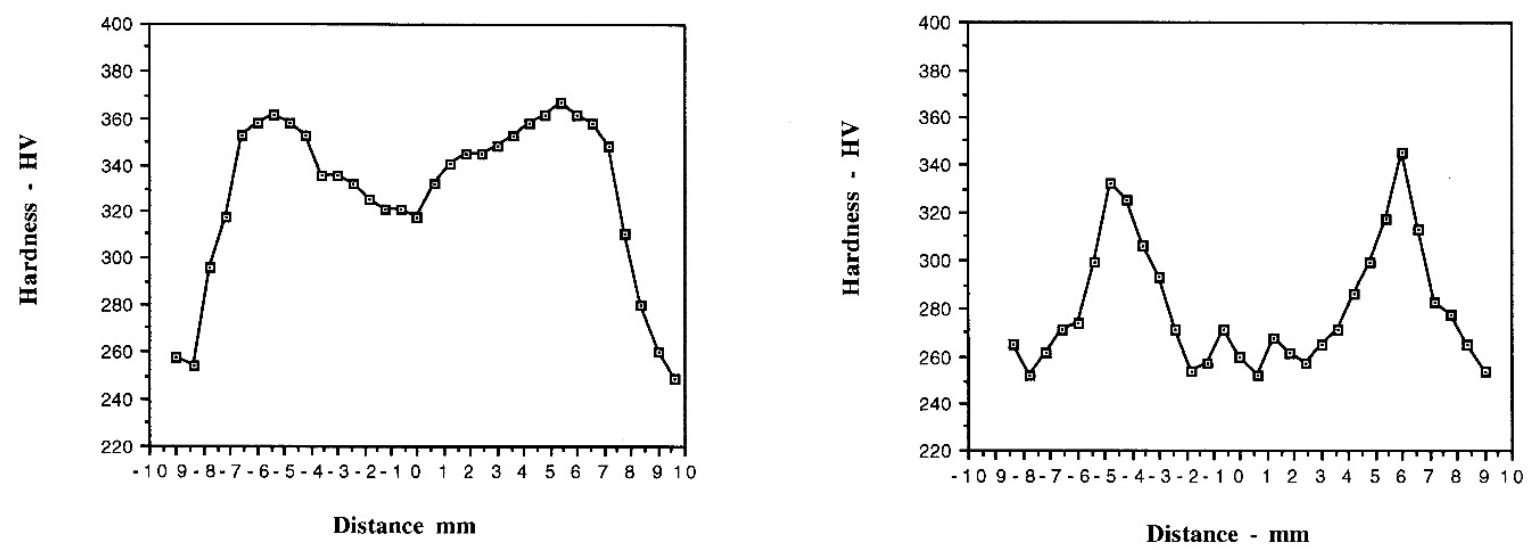

Figure 8. Hardness curves (HV5) along the surface centreline of simulation samples of EM812, heated to peak temperatures of about $1350^{\circ} \mathrm{C}$, with pre-heats of $20^{\circ} \mathrm{C}$ (left) and $200^{\circ} \mathrm{C}$ (right) [5]. The point 0 (origin) corresponds to the point of attachment of the control thermocouple on the sample surface at the mid-thickness and mid-length of the bar.

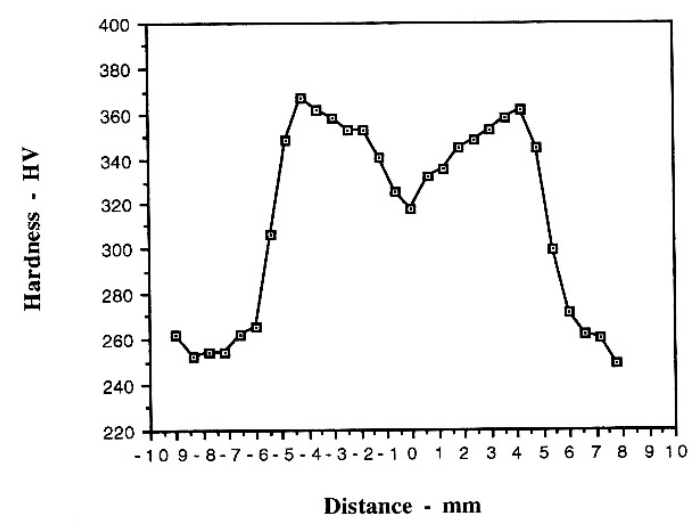

(a)

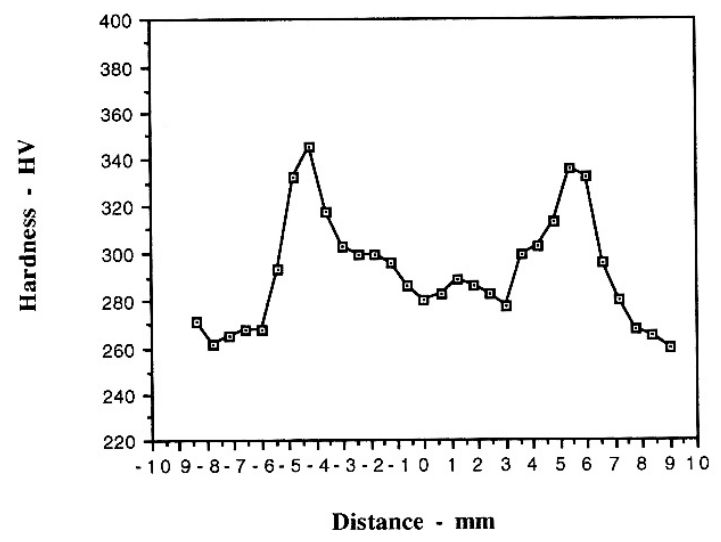

(b)

Figure 9. Hardness profiles (HV5) for simulated samples heated to peak temperatures of about $1100^{\circ} \mathrm{C}$ with pre-heats of (a) $20^{\circ} \mathrm{C}$ and (b) $200^{\circ} \mathrm{C}$.

The hardness profile was symmetrical about the origin with the maxima being about $365 \mathrm{HV}$ for no preheat and peak temperatures of $1350^{\circ} \mathrm{C}$ and $1100^{\circ} \mathrm{C}$ (Figures 8(a) and 9(a)). The peak hardness occurred at about $\pm 5 \mathrm{~mm}$ from the origin. This hardness value is relatively close to that 
measured for the actual weld (380 HV, see Figure 3(a)). Similarly, the hardness peaks shown in Figures 8 (b) and 9(b) for the simulated $200^{\circ} \mathrm{C}$ preheat (about $340 \mathrm{HV}$ ) were close to that of the actual weld (320 HV, see Figure 3(b)).

Although the selected $1100^{\circ} \mathrm{C}$ peak temperature was nominally for simulation of the GRHAZ, this temperature is at the upper bound of the range considered appropriate for this HAZ sub-zone and hence the austenite grain size would be expected to be relatively large. This factor may account for the apparent insensitivity of the hardness profiles recorded in Figures 8 and 9 to the selected peak temperature. However, there are slight differences in displacement of the hardness peaks from the origin. The $1350^{\circ} \mathrm{C}$ treatment shows average displacements of about $5 \mathrm{~mm}$ and $5.5 \mathrm{~mm}$ from the origin for preheats of $20^{\circ} \mathrm{C}$ and $200^{\circ} \mathrm{C}$, respectively, whereas the $1100^{\circ} \mathrm{C}$ peak temperature resulted in smaller displacements from the origin (approximately $4 \mathrm{~mm}$ and $5 \mathrm{~mm}$ for preheats of $20^{\circ} \mathrm{C}$ and $200^{\circ} \mathrm{C}$ ). This trend is consistent with the hypothesis that peak hardness corresponds to a particular temperature and austenite grain size range. A lower peak temperature at the origin should therefore shift the peak hardness towards the origin.

Measurements of the prior austenite grain sizes with distance along the centreline of simulation samples are shown in Figure 10 for the case of a preheat of $200^{\circ} \mathrm{C}$. Similar data were obtained for the other preheat temperatures, indicating that the austenite grain size gradient depended strongly on peak temperature and was relatively insensitive to the preheat temperature. The average grain size fell from a maximum at the origin, corresponding to the set peak temperature, to a minimum less than about $10 \mu \mathrm{m}$ at a distance of about $5 \mathrm{~mm}$ from the origin.

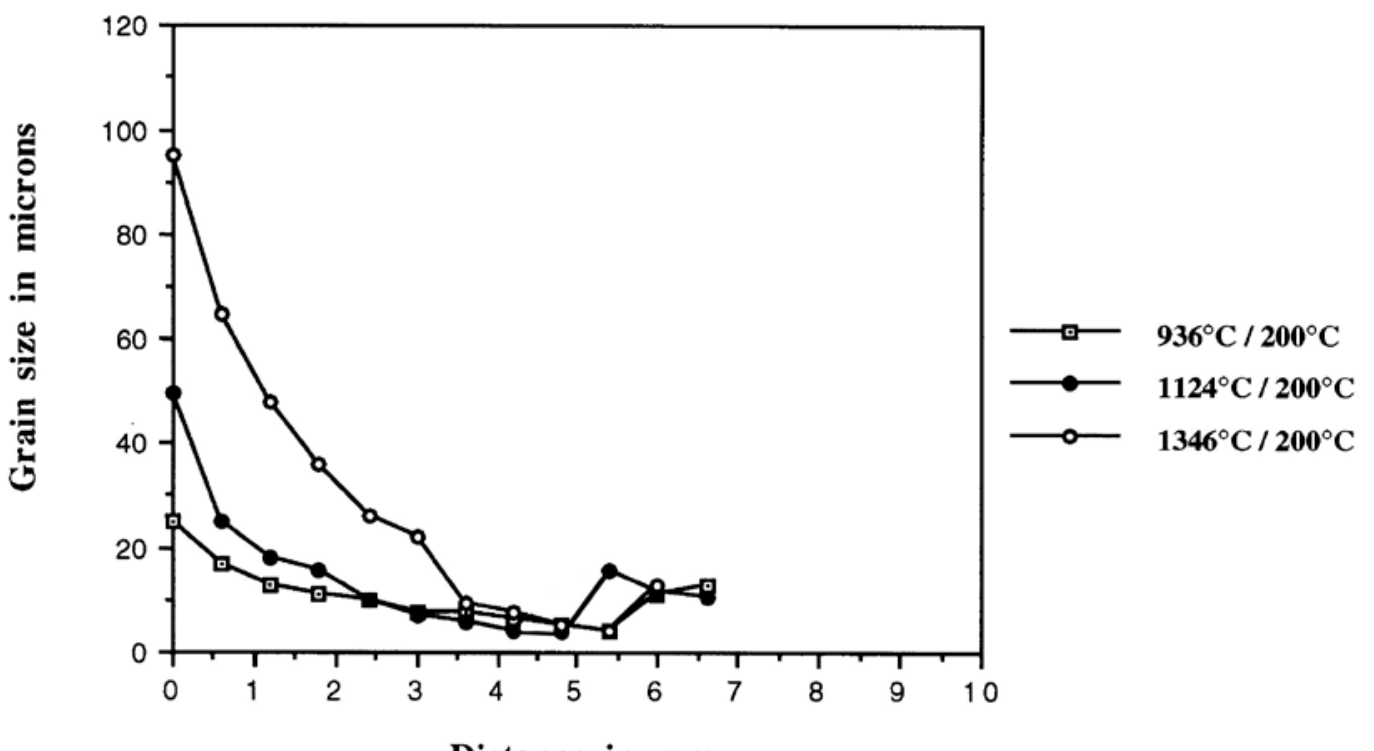

Distance in $\mathbf{m m}$.

Figure 10. Prior austenite grain size as a function of distance from the origin in weld simulation samples. 
The hardness peaks shown in Figures 8 and 9 occur at distances of 5-6 mm from the central point and therefore correspond to microstructures generated from regions with prior austenite grains $<10 \mu \mathrm{m}$ in average diameter. The drop in hardness beyond the peaks is likely to be due to the combination of fine austenite grains and lower cooling rates from lower peak temperatures which reduces the hardenability sufficiently for allotriomorphic ferrite to form at the expense of bainitic ferrite. Further, for peak temperatures that do not generate complete re-austenitisation, a mixed microstructure of coarsened undissolved ferrite and carbide would be expected that would steeply reduce the HAZ hardness.

The grain size data given Figure 10 can also be plotted at a function of predicted temperature with distance along the bar sample by using Equation (1). Figure 11 shows this type of plot for the samples subjected to a simulated $200^{\circ} \mathrm{C}$ preheat. The arrows along the $\mathrm{x}$-axis indicate the grain sizes and the temperatures corresponding to the peak hardness values found for peak temperatures of $1346^{\circ} \mathrm{C}$ (right arrow), $1124^{\circ} \mathrm{C}$ (middle arrow) and $936^{\circ} \mathrm{C}$ (left arrow). The average grain size in the centre of each sample was $95 \mu \mathrm{m}$ for $1346{ }^{\circ} \mathrm{C}, 50 \mu \mathrm{m}$ for $1124{ }^{\circ} \mathrm{C}$ and $25 \mu \mathrm{m}$ for $936{ }^{\circ} \mathrm{C}$. The corresponding hardness values were 268, 287 and $316 \mathrm{HV}$, indicating that the hardness increased by $48 \mathrm{HV}$ points from the GCHAZ to the lower bound of the GRHAZ. This hardness increment is associated with a reduction in austenite grain size by approximately a factor of 4 and this result is also consistent with the finding that peak hardness was displaced from the bar centre to a region with a significantly lower austenite grain size. The peak hardness values correspond to prior austenite grain sizes well less than $10 \mu \mathrm{m}$ and temperatures in the range $840^{\circ} \mathrm{C}$ to $1010^{\circ} \mathrm{C}$.

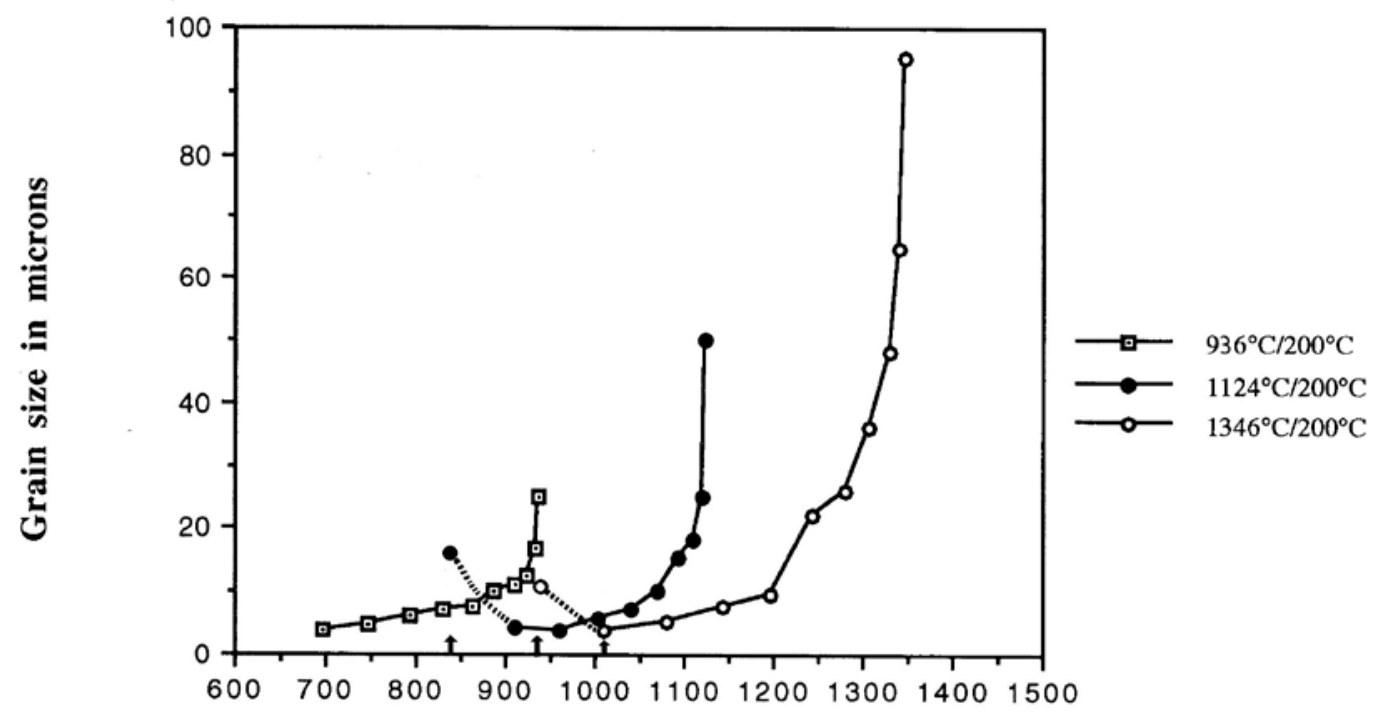

Temperature ${ }^{\circ} \mathrm{C}$

Figure 11. Prior austenite grain size as a function of predicted temperature along bar samples subjected to simulated thermal cycles with peak temperatures of $936^{\circ} \mathrm{C}, 1124^{\circ} \mathrm{C}$ and $1346{ }^{\circ} \mathrm{C}$. 


\subsection{Comparison of actual and simulated welds}

The grain size variation across the actual HAZ as a function of pre-heat is shown in Figure 12. The prior austenite grain size fell from a value higher than $30 \mu \mathrm{m}$ near the fusion boundary to about $10 \mu \mathrm{m}$ at a distance of $0.7 \mathrm{~mm}$ and to less than $5 \mu \mathrm{m}$ at $1.2-2.0 \mathrm{~mm}$. The dashed curve at a distance greater than 2 $\mathrm{mm}$ from the fusion boundary schematically indicates the rise in "grain size" associated with the ICHAZ and an increase towards the base metal average grain size of $10 \mu \mathrm{m}$. The HAZ width was about $2.5 \mathrm{~mm}$ and, in sharp contrast, the simulation samples were thermally affected to a distance of about 8-10 mm on either side of the bar centre. Therefore, the thermal gradient across the HAZ of the actual welds was considerably steeper.

The occurrence of peak hardness at about $1.5 \mathrm{~mm}$ from the fusion boundary (Figure 3) corresponds to a prior austenite grain size of about $5 \mu \mathrm{m}$ (Figure 12). Therefore, the results for both the actual welds and the simulations reinforce the conclusion that the peak hardness occurs in regions where the prior austenite grain size is less than $10 \mu \mathrm{m}$.

The grain size obtained for thermal simulation to a peak of about $1350^{\circ} \mathrm{C}$ was approximately double that measured for the actual weld in the GCHAZ. This observation is common for simulation experiments and must arise from different thermal conditions and microstructural environments in the two cases. For example, the actual weld HAZs were analysed at the weld root, whereas the simulated samples were examined on the surface of the bar at its central point. Nevertheless, it is evident that for both the actual weld HAZ and the simulation samples the hardness peak does not correspond to the region of the HAZ with maximum prior austenite grain size.

It should be noted that the region of the test bar appropriate to simulation of the actual thermal cycle is confined to a volume of about $5 \mathrm{~mm}$ width at the centre of the bar and the cooling profiles at other positions were neither controlled or measured. However, the peak temperature reached as a function of distance along the bar at can be reasonably estimated by using Widgery’s equation, as shown by Figure 7. It is possible that the region of the test bar exhibiting maximum hardness could be associated with a higher cooling rate than in the bar centre because of the proximity of the water cooled grips. A faster rate might be expected to displace transformation of the austenite to lower temperatures, thereby increasing the dislocation density and therefore, the hardness. It is also possible that martensite could form rather than bainitic ferrite, but Figure 3 indicates that the cooling time $\Delta \mathrm{t}_{8-5}$ would have to be decreased from $20 \mathrm{~s}$ to $\leq 10 \mathrm{~s}$ for treatments with no preheat. Even if martensite did form there is little evidence from studies of the bainite-martensite transition in low carbon steels that a significant increase in hardness would occur [14]. Moreover, the relatively low peak temperature corresponding to peak 
hardness, together with any increase in the local cooling rate, could inhibit solution of carbide in austenite and raise both $\mathrm{Ms}$ and Bs, thereby reducing hardness. These considerations indicate that any cooling rate increase in regions of peak hardness is unlikely to have a substantial effect on hardness.

The only accurately known cooling rates are those of the bar centre and, for peak temperatures of $1346^{\circ} \mathrm{C}, 1124^{\circ} \mathrm{C}$ and 936 and $200^{\circ} \mathrm{C}$ preheat, the measured Vickers hardness values were: 269, 287 and 316 (see Figure 11). The hardness difference of $47 \mathrm{HV}$ points between the GCHAZ and the lower range GRHAZ is consistent with the hardness profile of the actual weld for $200^{\circ} \mathrm{C}$ preheat, Figure 3(b).

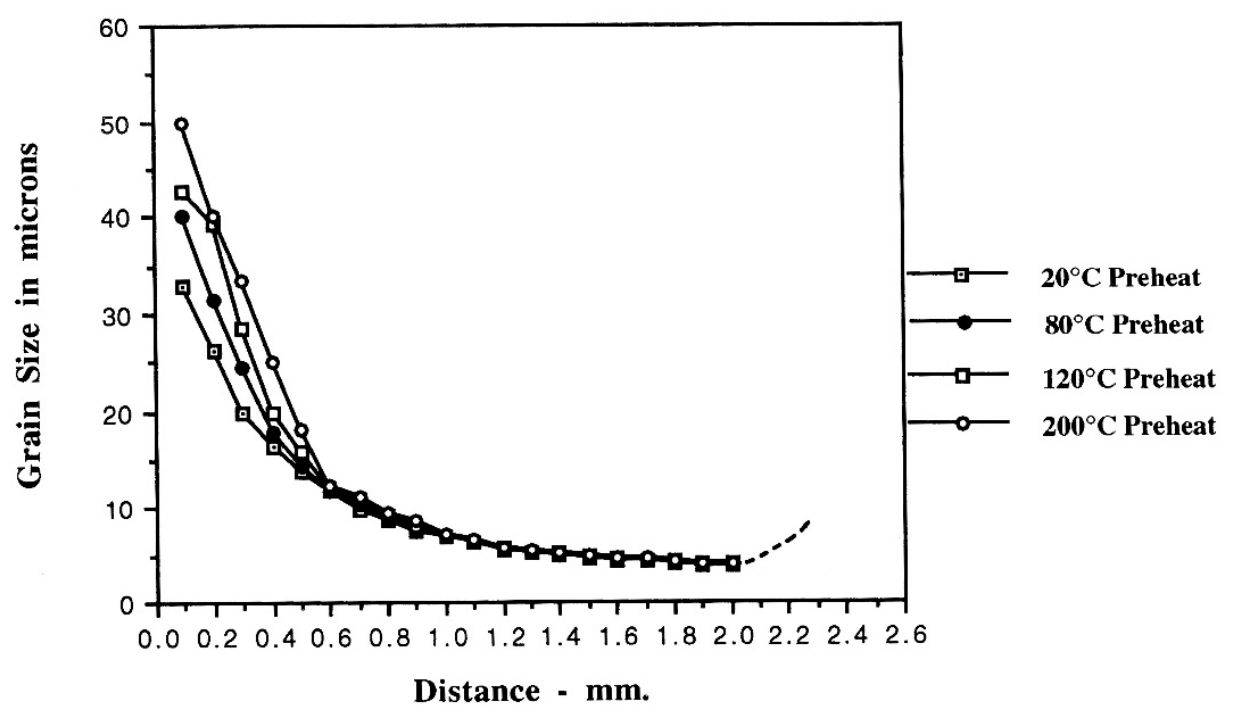

Figure 12. Prior austenite grain size as a function of distance from the fusion line for BOP welds at $2.58 \mathrm{~kJ} / \mathrm{mm}$ and the indicated preheat temperatures.

\subsection{Effect of boron}

The addition of up to about 25 ppm B in low carbon steels significantly retards the formation of ferrite at austenite grain boundaries without affecting decomposition to bainite. Martensite formation is promoted on rapid quenching and, when $\mathrm{Mn}, \mathrm{Cr}$ and Mo are also present, the bainite $\mathrm{C}$ curve becomes "flat-topped", resulting in transformation to bainite over a wide range of plate thicknesses during continuous cooling. However, it is essential to Al-kill the steel and/or to microalloy with $\mathrm{Ti}$ or $\mathrm{V}$ to prevent formation of boron nitride or oxide, thereby allowing B segregation to austenite boundaries, where it inhibits nucleation of ferrite [15]. Excess B (> $35 \mathrm{ppm}$ ) can react to form $\mathrm{Fe}_{2} \mathrm{~B}$ and/or $\mathrm{M}_{23}(\mathrm{CB})_{6}$ particles at austenite boundaries, enhancing ferrite nucleation [15]. The alloy design of the steel investigated in this report is consistent with these principles.

\subsection{Bainite hardness and strength}


The tensile strength of low carbon martensitic/bainitic steels depends strongly on the transformation temperature, with the strength of bainite being similar to that of martensite (about $1150 \mathrm{MPa}$ ) at a 50\% transformation temperature $\left(\mathrm{B}_{50}\right)$ of about $430^{\circ} \mathrm{C}[15]$. Therefore, although the "martensitic" steel examined in the current work transforms to bainitic ferrite for the welding conditions used, the strength and hardness remain high and close to those of untempered martensite.

Bainite transformation temperatures can be changed by alloying variations within the range of 0.05$0.2 \% \mathrm{C}$ and by adjusting the contents of $\mathrm{Mn}, \mathrm{Cr}$, Mo and other common alloying elements. In fact, good agreement between observed and predicted tensile strengths was obtained by Pickering [15] using an empirical equation based only on alloy composition. He rationalised this result on the basis that strength is proportional to $\mathrm{B}_{50}$, which is proportional to composition. Mechanistically, this relationship implies that transformation temperature is dominant in determining strength through defects/strain fields arising from the transformation volume change and alloy supersaturation, plus the scale and distribution of substructural features such as laths, lath packets, dislocation cells, residual C-enriched constituents (MA islands) and carbide precipitates.

Although the type of steel examined in this paper is sufficiently hardenable to produce a minimum yield strength of $690 \mathrm{MPa}$, it is hardenable with respect to both martensite and bainitic ferrite. The significant concentrations of $\mathrm{Mn}, \mathrm{Cr}$ and Mo in the alloy (Table 1) ensure that the $\mathrm{B}_{\mathrm{S}}$ curve is flat-topped and displaced to relatively low temperatures. Both low carbon martensite and bainitic ferrite consist of fine ferritic laths with high dislocation densities. The strengthening obtained is a sensitive function of temperature range of formation and the cooling rate through that range. Rapid quenching lowers the temperature of formation to the $\mathrm{M}_{\mathrm{S}}-\mathrm{M}_{\mathrm{F}}$ range, produces a more $\mathrm{C}$-saturated ferrite, increases the dislocation density and limits dislocation annihilation and auto-tempering. Bainitic ferrite formation in relatively low carbon steels occurs over a slightly higher temperature range at slower cooling rates, with carbon partitioning to remnant austenite which becomes isolated in small islands between laths. This austenite can partially transform to a higher carbon martensite at lower temperatures, producing martensite-austenite (MA) constituent. The bainitic hardenability of the steels investigated is relatively high, with bainite start temperatures $\left(\mathrm{B}_{\mathrm{S}}\right)$ of about 450 to $500^{\circ} \mathrm{C}$, Figure 3. Further, $\mathrm{B}_{\mathrm{S}}$ is intercepted for cooling rates typical of arc welding, without austenite transformation to softer/lower strength ferritic products such as polygonal ferrite $\alpha_{P}$ and quasi-polygonal ferrite $\alpha_{Q}$ [9].

The measured weldment hardness profiles for both actual and simulated welds clearly show that peak HAZ hardness for the welded $690 \mathrm{MPa}$ steel occurs in a fine grained region that is not closely adjacent to the fusion boundary. Therefore, despite a smaller $d_{A}$ in the GRHAZ, bainitic ferrite still forms with a higher hardness than the GCHAZ (also bainitic ferrite) because of the grain-size contribution. The 
refined prior austenite grain size remains a structural entity within the bainitic structure (i.e. austenite grain boundaries are not obliterated as they are when $\alpha_{P}$ and/or $\alpha_{Q}$ are formed). Therefore, it has been proposed [2] that an austenite grain size effect occurs, as shown by Grange [16] for AISI 4340.

In fundamental terms, yielding occurs when dislocations can move sufficiently large distances to produce observable plastic strain. The external stress has to be high enough for dislocations to bypass or cut obstacles that collectively present an internal stress field opposing their motion. Decreasing $d_{A}$ increases the surface area/unit volume of grain boundary and promotes refinement of the bainitic laths. Honeycombe and Bhadeshia [17] proposed that the strength of martensite or bainite can be estimated by summing the effects of the following barriers to dislocation motion:

a. the intrinsic strength of iron $\left(\sigma_{\mathrm{Fe}}\right)$;

b. substitutional alloy strengthening $\left(\Sigma \mathrm{x}_{\mathrm{i}}\left(\sigma_{\mathrm{ss}}\right)_{\mathrm{i}}\right)$;

c. interstitially dissolved carbon $\left(\sigma_{\mathrm{C}}\right)$;

d. the inverse of the lath/plate width $\left(\mathrm{K}_{\mathrm{L}} \mathrm{L}^{-1}\right)$; and

e. the dislocation density $\left(K_{D} \rho^{0.5}\right)$.

The subscripts $\mathrm{L}$ and $\mathrm{D}$ refer to constants $(\mathrm{K})$ associated with lath size and dislocation density $\rho$ and $\mathrm{x}_{\mathrm{i}}$ is the concentration of the $\mathrm{i}^{\text {th }}$ element that contributes a solid solution strengthening increment, $\left(\sigma_{\mathrm{ss}}\right)_{\mathrm{i}}$. The last three terms quantify barriers that are due to solute carbon, substructural refinement and dislocations, and are expected to be the dominant factors in determining the strength. Factor (d) quantifies the microstructural refinement effect through the inverse of the bainitic lath/plate width. Prior austenite grain size is also used as an index of microstructural refinement and can be considered to have a direct relationship to lath size because the grain boundaries provide nucleation sites for bainite/martensite formation. Therefore the structural refinement effect can be accounted for empirically by using $K_{L} L^{-1}$ or $\mathrm{K}_{\mathrm{Y}} \mathrm{d}_{\mathrm{A}}^{-0.5}$.

Prediction of the strength/hardness of the different microstructures produced in the current experiments is difficult because heating to different peak temperatures and the application of different preheats will vary the last four terms that contribute to the overall strength. The thermal profile over the high temperature range will determine the extent of dissolution of carbide and therefore the content of carbon and those of the strong carbide forming elements (Mn, Cr and Mo) in solution in austenite.

However, if it is assumed that prior austenite grain size is the dominant factor and the remaining factors provide a constant base strength, $\sigma_{0}$, the contribution of grain size can be checked for consistency with the observed hardness differences. The effect of prior austenite grain size is quantified by the Hall-Petch equation: 
$\sigma=\sigma_{0}+\mathrm{K}_{\mathrm{Y}} \mathrm{d}_{\mathrm{A}}{ }^{-0.5}$

where $\sigma$ is the yield strength in MPa and $d_{A}$ is the grain size in mm. Linear correlation between yield strength and hardness (HV) has been reported by Pavlina and Van Tyne [18] for steels with a wide range of yield strengths:

$\sigma=-90.7+2.876 \mathrm{HV}$

Combining Equations (2) and (3) results in the equation:

$-90.7+2.876 \mathrm{HV}=\sigma_{0}+\mathrm{K}_{\mathrm{Y}} \mathrm{d}_{\mathrm{A}}^{-0.5}$

If it is assumed that $\sigma_{0}$ is constant for two different thermal treatments that produce different prior austenite grain sizes and hardness values; and that the $\mathrm{K}_{\mathrm{Y}}$ value of $21.3 \mathrm{MPa} \cdot \mathrm{mm}^{1 / 2}$ determined by Grange [15] for martensitic AISI 4340 steel is applicable, then the following equation can be derived for treatments 1 and 2:

$2.876 \mathrm{HV}_{1}-21.3\left(\mathrm{~d}_{\mathrm{A}}\right)_{1}{ }^{-0.5}=2.876 \mathrm{HV}_{2}-21.3\left(\mathrm{~d}_{\mathrm{A}}\right)_{2}{ }^{-0.5}$

If treatment 1 is taken as that which produces the thermal profile and the associated hardness $\mathrm{HV}_{1}$ and grain size $\left(d_{A}\right)_{1}$ in the bar centre, then the peak hardness $H_{2}$ can be predicted on the basis of the associated austenite grain size $\left(\mathrm{d}_{\mathrm{A}}\right)_{2}$, which is taken on the basis of Figures 10 and 11 to be $5 \mu \mathrm{m}$. Table 3 records predicted and measured hardness values $(\mathrm{HV})_{2}$ for a number of the thermal simulations conducted. Two values were used for $\mathrm{HV}_{1}$ - the minimum measured hardness and the average hardness over the central distance of $\pm 2.4 \mathrm{~mm}$ which is taken to define the extent of the simulated weld zone. The measured hardness values $\mathrm{HV}_{2}$ were consistently lower than the predicted values.

Table 3. Calculated peak hardness $\mathrm{HV}_{2}$ for simulation samples based on variation in prior austenite grain sizes, $\left(d_{A}\right)_{1}$ and $\left(d_{A}\right)_{2}$, and measured minimum and average hardness values $H V_{1}$ in the central region of the bar.

\begin{tabular}{|l|l|l|l|l|l|l|l|l|}
\hline $\begin{array}{l}\text { Peak T } \\
{ }^{\circ} \mathrm{C}\end{array}$ & $\begin{array}{c}\text { Preheat } \\
{ }^{\circ} \mathrm{C}\end{array}$ & $\begin{array}{l}\mathrm{HV}_{1} \\
\text { Min }\end{array}$ & $\begin{array}{c}\mathrm{HV}_{1} \\
\text { Ave }\end{array}$ & $\begin{array}{l}\left(\mathrm{d}_{\mathrm{A}}\right)_{1} \\
\mu \mathrm{m}\end{array}$ & $\begin{array}{c}\text { Calc. } \mathrm{HV}_{2} \\
\text { Min }\end{array}$ & $\begin{array}{l}\text { Calc. } \mathrm{HV}_{2} \\
\text { Ave }\end{array}$ & Meas. $\mathrm{HV}_{2}$ & $\Delta \mathrm{HV}$ \\
\hline 936 & 200 & 303 & 316 & 25 & 345 & 358 & 325 & -20 \\
\hline 1100 & 20 & 329 & 340 & 50 & 400 & 411 & 365 & -35 \\
\hline 1100 & 200 & 277 & 287 & 50 & 348 & 358 & 334 & -14 \\
\hline 1350 & 20 & 317 & 337 & 95 & 398 & 418 & 365 & -33 \\
\hline 1350 & 200 & 260 & 269 & 95 & 341 & 350 & 339 & -2 \\
\hline
\end{tabular}

The discrepancy $\Delta \mathrm{HV}$ between measured hardness and that predicted based on the minimum value of $(\mathrm{HV})_{1}$ was up to $35 \mathrm{HV}$ points and was higher for the treatments with no preheat. Although the measured and predicted hardness values are not in close agreement, the calculated results may be limited in accuracy because the methodology involves an element of statistical uncertainty and some of the 
assumptions made in the analysis are questionable. For example, the value of $\mathrm{K}_{\mathrm{Y}}$ in Equation (2) relates to martensitic 4340 steel and may not be appropriate for the auto-tempered bainitic ferrite microstructures observed for the present case. Secondly, the correlation given by Equation (3) has a standard error associated with the constant term of 22.3 MPa together with a standard error of $100 \mathrm{MPa}$ for the linear regression equation developed over the hardness range of 129 - 632 HV [18]. The limitations of the equation are also evident in its estimate of the yield strength of the base EM812 alloy. Using the measured average hardness of $268 \mathrm{HV}$, the predicted yield strength of $680 \mathrm{MPa}$ is well below the measured value of $754 \mathrm{MPa}$ for the steel investigated. Similar uncertainty applies to the combined Equation (4), as well as the predictions of $\mathrm{HV}_{2}$ calculated from Equation (5) which is based on a constant value for $\sigma_{0}$. The assumption that $\sigma_{0}$ is unchanged when comparing two different heat treatments is not robust, because the strength contribution factors (b), (c) and (d) are likely to differ for the two treatments. Therefore, the level of disagreement between measured and calculated hardness values does not invalidate the hypothesis that the displaced hardness peak (DHP) effect observed in the HAZ of Q\&T steels is due to austenite grain refinement without a change in microstructure.

The importance of prior austenite grain has been demonstrated by the simulation work which showed that the peak hardness in simulation samples occurred in regions of lower prior austenite grain size. Although this phenomenon was observed in regions where the thermal cycle was incompletely defined, the trend of increasing hardness with decreasing grain size was also found in the central region of the bar where the cooling rate was controlled.

\subsection{HAZ microstructure and hydrogen induced cold cracking}

A weldment introduces a structural heterogeneity that locally changes the mechanical properties relative to the base steel. In effect, a structural notch is introduced in company with physical notches due to weld defects such as sharp profile changes, undercut, lack of fusion, weld metal porosity and lack of fusion. Notches concentrate stress, which is inevitably present due the weld configuration, and thermal and transformation stresses. Hardening of the HAZ by martensite/bainite is a serious issue because of its susceptibility to HICC in the presence of even minute amounts of hydrogen and local stress concentration. Martensitic/bainitic microstructures with high hardness generally exhibit low fracture toughness and can be regarded as more HICC-susceptible than microstructures of lower hardness and higher fracture toughness. Consequently, significant effort is devoted to defining welding procedures that result in sufficiently slow cooling to ensure the absence of hard martensitic/bainitic structures and to allow time for hydrogen effusion. The GCHAZ is generally considered to be the region of the weldment that is most susceptible to HICC because of the high hardness and proximity to potential stressconcentrating defects. However, the present results suggest that, because of its higher hardness, the GRHAZ has a more HICC-susceptible microstructure, thus shifting the critical crack zone away from 
the GCHAZ-fusion boundary region. Although it can be argued that the greater refinement of the structure of the GRHAZ would increase its toughness, this refinement provides no security against HICC. Beachem [20] showed that hydrogen is capable of initiating cracking in microstructures of alloy steels that exhibited high fracture resistance under $\mathrm{H}$-free conditions. In effect, therefore, if a critical stress concentration and a critical hydrogen concentration are reached at a particular microstructural site, HICC will occur regardless of the microstructure.

Evidence supporting the hypothesis about the potentially higher HICC-susceptibility of the GRHAZ is provided in work by Zimmer et al. [19] on the hydrogen distribution in welded high strength Q\&T steels and its effect on the true strain at fracture. The data indicated that the critical hydrogen concentration required for cracking was lower in the GRHAZ than the GCHAZ, implying that the GRHAZ microstructure was more susceptible to HICC.

\section{Conclusions}

The results show unambiguously that the HAZ hardness gradients produced in the Q\&T steel investigated differ distinctly from those found in steels of lower carbon equivalent. The peak HAZ hardness is displaced from the GCHAZ to the GRHAZ. Thermal simulation experiments confirmed that hardness can be significantly increased by austenite grain refinement. Therefore, the displaced peak hardness effect observed in the HAZ of welded Q\&T steels is considered to originate from grain and substructure refinement, in concert with a bainitic hardenability that is high enough to ensure the formation of bainitic ferrite for the cooling rates and prior austenite grain sizes generated by the arc welding process. The displaced peak hardness also implies that the HAZ microstructure with the highest susceptibility to HICC in Q\&T steels is remote from the fusion boundary, within the GRHAZ.

\section{Acknowledgements}

The authors are grateful for the contributions of research students of the University of Wollongong, in particular, Alan Giumelli, Sanjay Dani, Liam Bell and Wayne Staff. We also gratefully acknowledge CSIRO MT, Adelaide, for providing the welded samples and Bisalloy Steels Pty Ltd for the steel plate.

\section{References}

1. The Making, Shaping and Treating of Steel: $8^{\text {th }}$ Ed, USS Corp., Pitts., PA, 1964, 1092-3

2. W. Pang, N. Ahmed, D. Dunne: "Hardness and microstructural gradients in the heat affected zone of welded low-carbon quenched and tempered steels”, Australasian Weld. J. - WRS, 56(2) (2011) 36-48. 
3. International Institute of Welding, IIW Doc. IX-535-67, 1967

4. D.P.Dunne: “Weldable Copper Strengthened Low Carbon Steels”, Proceedings of HSLA'95 Conference, Beijing, Oct. 1995, 90-98.

5. W. Pang: "The Structure and Properties of the Heat Affected Zone of Structural Plate Steels Welded by High Productivity Processes”, Ph.D Thesis, University of Wollongong, 1995.

6. D.P. Dunne and W. Pang: "Structural and Hardness Gradients in the Heat Affected Zone of Welded Low Carbon Martensitic Steels”, Mater. Sci. Forum, 738-739 (2013) 206-211.

7. S. G. Dani: "The effect of pre-heat on the structure and properties of the HAZ of a welded quenched and tempered steel plate”, Master of Engineering (Hons) Thesis, University of Wollongong, 1993.

8. A. Guimelli, W. Pang, G. Hamilton, D. Dunne: "Weld Thermal Cycle Simulation Using Computer Controlled Resistance Heating”, Pacrim Weldcon '92, Proc. $40^{\text {th }}$ National Conf. of Welding Technology Institute of Australia, Vol. 2, WTIA, Darwin, 1992, Paper 45.

9. Atlas for Bainitic Microstructures: Vol.1, Bainite Committee of Iron and Steel Inst.of Japan, 1992

10. Liang Chen: "Characterisation of transverse cold cracking in weld metal of a high strength quenched and tempered steel”, Ph.D Thesis, The University of Wollongong, 2000.

11. D. Rosenthal: Trans. ASME, 68 (1946) 167.

12. K. Easterling: "Introduction to the Physical Metallurgy of Welding”, Butterworths, London, 1983.

13. D.J. Widgery: “The Design and Use of a Resistance Heated Weld Simulator”, Seminar Handbook, The Welding Institute, 1972, 15.

14. D. Dunne: "Ferrite Morphology and Residual Phases in Continuously Cooled Low Carbon Steels”, Materials Forum, 23 (1999) 63-76.

15. F.B. Pickering: Physical Metallurgy and the Design of Steels, App. Sci. Publishers Ltd, UK, 1978.

16. R.A.Grange: Trans Q. ASM, 59 (1966) 26.

17. R.W.K. Honeycombe, H.K.D.H. Bhadeshia: Steels - Microstructure and Properties, $2^{\text {nd }}$ Edition, Edward Arnold, London, 1995.

18. E.J Pavlina, C.J. Van Tyne: Journal of Materials Engineering and Performance, 17 (2008) 888-893.

19. P. Zimmer, Th. Bollinghaus, Th. Kannengiesser: "Effects of Hydrogen on Weld Microstructure and Mechanical Properties of High Strength Steels S690Q and S1100SQ”, IIW Document III-A-141-04, 2004.

20. C.D. Beachem: Metallurgical Transactions, 3(2) (1972) 437. 
